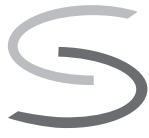

\author{
KS. JACEK SOPRYCH \\ UPJPII Kraków \\ WTST \\ ORCID: 0000-0002-5595-7366
}

\title{
ELENCHUS PROBOSZCZÓW I WIKARIUSZY PILZNEŃSKICH 1786-1959
}

$\mathrm{R}$ ękopis Elenchus. Omnium Parochorum, Administratorum, Capellanorum localium, Cooperatorum Parochiae Pilzno qui penes Ecclesiam hanc ab A 1410 usque ad novissima tempora munia spirytualia obibant eqvectantes vivi Memento penes Missam defuncti preter Memento etiam s. Nocturnum cum Laudibus omni anno juxta Constit: Consistorialem de Anno 1829 x 1848 Nro 2284 X 1592 a grato Successore ac pio Confratre. Conscripsit Ferdinandus Celarski Prae. Esia. Pilzn. a $1859^{2}$ sporządzony przez pilźnieńskiego proboszcza Ferdynanda Celarskiego, uzupełniony przez jego następców i doprowadzony do połowy XX w., zawiera wykaz proboszczów i wikariuszy pracujących w kościele pw. św. Jana Chrzciciela w Pilźnie³ Katalog ten jest osobnym źródłem, pisanym ręką wielu autorów, prawdopodobnie kapłanów. Rękopis o wymiarach 23x35 cm zapisany jest na 26 stronach w zasadniczej części w języku łacińskim ${ }^{4}$. Na 13 z nich odnotowanych jest 235 nazwisk kapłanów pracujących w Pilźnie, począwszy od Filipa Fallenberga, który przybył do Pilzna w 1410 r., aż po dwóch ostatnich wpisanych do Elenchusa wikariuszy przybyłych do Pilzna 1 sierpnia 1959 r.: ks. Mieczysława Pytkę i ks. Bronisława Skrzeka5 . Rękopis został podzielony na dwie części: pierwsza z nich została doprowadzona do roku 1786, czyli do utworzenia diecezji tarnowskiej ${ }^{6}$. Druga natomiast zawiera wykaz duchownych od 1786 do 1959 r. ${ }^{7}$

\footnotetext{
1 Ks. Jacek Soprych - asysytent w katedrze Patrologii i historii Kościoła Wydziału Teologicznego Sekcja w Tarnowie UPJPII w Krakowie, wykładowca historii Kościoła, rektor Wyższego Seminarium Duchownego w Tarnowie.

2 Archiwum Parafialne w Pilźnie (dalej: APP), Elenchus, bez sygn., s. 3.

3 Pilzno - średniowieczne miasteczko w Dolinie Wisłoki, prawa miejskie nadane zostały przez króla Kazimierza Wielkiego 3 X 1354 r. Aktualnie w województwie podkarpackim, liczy ok 5 tys. mieszkańców.

4 J. Soprych, Elenchus. Omnium Parochorum, Administratorum, Capellanorum localium, Cooperatorum Parochiae Pilzno qui penes Ecclesiam hanc ab Anno 1410 ad 1786, „Saeculum Christianum”, 25/2018, s. 376.

5 APP, Elenchus, bez sygn., s. 5-18.

6 Pierwsza część została opublikowana drukiem w 25 numerze czasopisma „Saeculum Christianum”. Por. J. Soprych, Elenchus. Omnium Parochorum, Administratorum, Capellanorum localium, Cooperatorum Parochiae Pilzno qui penes Ecclesiam hanc ab Anno 1410 ad 1786, „Saeculum Christianum”, 25/2018, s. 376-389, wydawnictwo UKSW Warszawa.

7 Ta druga część jest przedmiotem niniejszej publikacji.
} 
Diecezję tarnowską erygował kanonicznie papież Pius VI bullą In suprema beati Petri cathedra $\mathrm{z}$ dnia 13 marca $1786 \mathrm{r}^{8}$ Parafia Pilzno od samego początku została ustanowiona siedzibą dekanatu, który obejmował kolegiatę w Tarnowie oraz 24 parafie: Lisia Góra, Wierzchosławice, Zbylitowska Góra, Pleśna, Siemiechów, Brzozowa, Jodłówka, Gromnik, Poręba Radlna, Piotrkowice, Łękawica, Tuchów, Skrzyszów, Ryglice, Szynwałd, Zalasowa, Jastrząbka Stara, Straszęcin, Pilzno, Łęki, Zwiernik, Lubcza i Jurków, 1 filię w Machowej, 3 miasta: Tarnów, Tuchów i Pilzno oraz 78630 wiernych ${ }^{9}$. Pilzneńscy proboszczowie byli też zasadniczo dziekanami dekanatu. Przysługiwał im tytuł prepozyta, gdyż w początkach XVII w. pilzneńska fara otrzymała tytuł prepozytury. Proboszczów wspomagali wikariusze. Na początku XIX w. ustalono, że w Pilźnie będzie pracować ich trzech. W praktyce jednak było dwóch, przy czym zdarzało się nieobsadzenie jednego z tych stanowisk. W końcu XIX w. utworzono w Pilźnie stanowisko katechety ${ }^{10}$.

Niżej zamieszczona tabela przedstawia wykaz kapłanów pracujących w Pilźnie od 1786 do 1959 r., sporządzony przez ks. Ferdynanda Celarskiego i jego następców.

Tab. 1. Wykaz kapłanów pracujących w Pilźnie od 1786 do 1959 r.

\begin{tabular}{|c|c|c|c|}
\hline $\begin{array}{l}\text { Numerus } \\
\text { positionis }\end{array}$ & $\begin{array}{l}\text { Nomen et Cognomen } \\
\text { Presbyterorum }\end{array}$ & $\begin{array}{l}\text { Dies et numerus } \\
\text { decreti aplication } \\
\text { Instituonis }\end{array}$ & $\begin{array}{l}\text { Tempus et modus eorum. Adventus } \\
\text { et existentiae cum meritis }\end{array}$ \\
\hline 106 & Mathias Skalski & 1787 & Vicar[ius] \\
\hline 107 & Adalbertus Zaborski & 1787 & 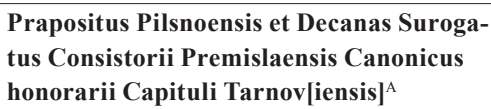 \\
\hline 108 & Joannes Żalnowski & 1790 & Vicarius \\
\hline 109 & Josephus Pawłowski & 1791 & Comendar[ius] \\
\hline 110 & Petrus Dzikowski & 1793 & Vicarius \\
\hline 111 & Sebaldus Kopaczyński & 1795 & Vicar[ius] Ord[o] August[ianorum] \\
\hline 112 & Nikolaus Brzóska & 1793 & Vicar[ius] Ord[o] August[ianorum] \\
\hline 113 & Casimirus Rojkowski & 1794 & Vicar[ius] \\
\hline 114 & Cantius Schulz & 1794 & Vicar[ius] \\
\hline 115 & Posidius Nowakowski & 1795 & Vicar[ius] Ord[o] August[ianorum] \\
\hline 116 & Jakobus Kulach & 1798 & Vica[rius] \\
\hline 117 & Josephus Modła & 1800 & Vicar[ius] \\
\hline 118 & Raphael Bańkowski & 1797 & Vic[arius] Ord[o] August[ianorum] \\
\hline 119 & Christianus Krzysztanowicz & 1802 & Vicar[ius] \\
\hline 120 & Joannes Rzeszotarski & 1803 & V[icarius] \\
\hline 121 & Sebastianus Fabisz & 1804 & V[icarius] \\
\hline 122 & Franciscus Kochott & 1804 & $\mathrm{~V}$ [icarius] \\
\hline 123 & Ignatius Sitkowski & 1808 & V[icarius] \\
\hline 124 & Valentinus Piechociński & 1809 & Vicar[ius] \\
\hline 125 & Joannes Zwoliński & 1809 & Vicar[ius] \\
\hline 126 & Jakobus Miętuszewski & 1810 & Vicar[ius] \\
\hline 127 & Gasparus Zajkowski & 1810 & Vicar[ius] \\
\hline
\end{tabular}

8 B. Kumor, Diecezja tarnowska. Dzieje ustroju i organizacji 1786-1985, Kraków 1985, s. 50-51.

9 Tamże, s. 54-55.

10 B. Stanaszek, Pilzno. Monografia miasta do 1945 roku, Pilzno 2018, s. 343. 


\begin{tabular}{|c|c|c|c|}
\hline $\begin{array}{l}\text { Numerus } \\
\text { positionis }\end{array}$ & $\begin{array}{l}\text { Nomen et Cognomen } \\
\text { Presbyterorum }\end{array}$ & $\begin{array}{l}\text { Dies et numerus } \\
\text { decreti aplication } \\
\text { Instituonis }\end{array}$ & $\begin{array}{l}\text { Tempus et modus eorum. Adventus } \\
\text { et existentiae cum meritis }\end{array}$ \\
\hline 128 & Christophorus Sroczyński & 1810 & Vicar[ius] \\
\hline 129 & Stanisaus Hadasik & 1811 & Vicar[ius] \\
\hline 130 & Michael Porębski & 1812 & Vicar[ius] \\
\hline 131 & Petrus Zych & 1814 & Vicarius \\
\hline 132 & Valentinus Pieszkiewicz & 1814 & Vicar[ius] \\
\hline 133 & Joannes Jedliński & 1815 & $\begin{array}{l}\text { Vicar[ius] Pilzn[ensis], Profesor Theolo- } \\
\text { giae Pastor[alis], Canonicus honorarius } \\
\text { Premysl[aensis] }\end{array}$ \\
\hline 134 & Antonuis Dygasiński & 1818 & Vicar[ius] \\
\hline 135 & Michael Sęczyński & 1818 & Vicar[ius] \\
\hline 136 & Paschalis Irzykiewicz & 1820 & Vicar[ius] Ord[o] Reform[atorum] \\
\hline 137 & Benevendur Pater & 1820 & V[icarius] \\
\hline 138 & Michael Rypiński & 1827 & Vicarius Societ[as] Jesu \\
\hline 139 & Vincentus Raciborski & 1827 & Vicarius Societ[as] Jesu \\
\hline 140 & Matheus Kłosowski & 1827 & Vicarius Societ[as] Jesu \\
\hline 141 & Michael Porębski & 1826 & $\begin{array}{l}\text { Ab anno } 1812 \text { ad } 1822 \text { vicarius Pilzn[aensis], } \\
\text { ad } 2 \text { Julii } 1826 \text { installatus qua praepositus } \\
\text { Ecclesiae Pilsnensis - mort. } 1838\end{array}$ \\
\hline 142 & Augustinus Markiewicz & 1827 & Vicarius Societ[as] Jesu \\
\hline 143 & Cantius Rudowski & 1827 & Vicar[ius] Ord[o] Bernardi[norum] \\
\hline 144 & Antonius Czermin & 1828 & Vicar[ius] \\
\hline 145 & Mathias Szaflarski & 1829 & Vicar[ius] \\
\hline 146 & Andreas Ciszek & $\begin{array}{l}1833 \\
-1838\end{array}$ & $\begin{array}{l}\text { Vicarius - } 1939 \text { administr[ator] Ecclesiae } \\
\text { Pilzno }\end{array}$ \\
\hline 147 & Antonius Weisskopf & 1835 & Vicarius \\
\hline 148 & Nikolaus Polończyk & 1837 & Vicar[ius] \\
\hline 149 & Paulus Białobrzeski & 1838 & Vicar[ius] \\
\hline 150 & Ferdinandus Celarski & 1838 & $\begin{array}{l}\text { Praposit[us] Ecclesiae Pilznensis, } 1840 \\
\text { Decanus Pilsnoensis, } 1857 \text { Canonicus } \\
\text { honorarius Capituli Tarnoviensis }\end{array}$ \\
\hline 151 & Andreas Jarończyk & 1838 & Vicarius \\
\hline 152 & Joannes Zdrzelski & 1841 & Vicarius \\
\hline 153 & Jakobus Piątek & 1843 & Vicarius \\
\hline 154 & Leon Kozłowski & 1845 & Vicarius \\
\hline 155 & Michael Garbiński & 1848 & Vicarius \\
\hline 156 & Maximilianus Stanisławski & 1848 & Vicarius \\
\hline 157 & Josephus Piątek & 1852 & Vicarius \\
\hline 158 & Marcelius Krzeczowski & 1852 & Vicarius \\
\hline 159 & Bartholomeus Zięciowski & 1863 & Vicarius \\
\hline 160 & Andreas Pajor & 1868 & Vicarius \\
\hline 161 & Adalbertus Kowalik & 1871 & $\begin{array}{l}\text { Vicarius, administr[ator] post mortem } \\
\text { Celarski, }\end{array}$ \\
\hline 162 & Simon Krupiński & 1872 & Vicarius \\
\hline 163 & $\begin{array}{l}\text { Ignatius de Vieniawa } \\
\text { Długoszowski }\end{array}$ & 1872 & $\begin{array}{l}\text { Canonicus honorarius Ecclesiae Cathedralis } \\
\text { Tarnoviensis }\end{array}$ \\
\hline 164 & Antonius Żądło & 1873 & Vicarius \\
\hline 165 & Romanus Lepiarz & 1874 & Vicarius \\
\hline
\end{tabular}




\begin{tabular}{|c|c|c|c|}
\hline $\begin{array}{l}\text { Numerus } \\
\text { positionis }\end{array}$ & $\begin{array}{l}\text { Nomen et Cognomen } \\
\text { Presbyterorum }\end{array}$ & $\begin{array}{l}\text { Dies et numerus } \\
\text { decreti aplication } \\
\text { Instituonis }\end{array}$ & $\begin{array}{l}\text { Tempus et modus eorum. Adventus } \\
\text { et existentiae cum meritis }\end{array}$ \\
\hline 166 & Antonius Skrudziński & 1874 & Vicarius \\
\hline 167 & Franciskus Szczudło & 1877 & Vicarius \\
\hline 168 & Josephus Lenartowicz & 1877 & Vicarius \\
\hline 169 & Petrus Grębosz & 1877 & Vicarius \\
\hline 170 & Joannes Bernacki & 1880 & Vicarius \\
\hline 171 & Alojsius Guńkiewicz & 1880 & Vicarius \\
\hline 172 & Blasius Sąsiadek & 1881 & Vicarius \\
\hline 173 & Matheus Skopiński & 1882 & Vicarius \\
\hline 174 & Alexander Sołtys & 1882 & Vicarius \\
\hline 175 & Joannes Olesiński & 1883 & Vicarius \\
\hline 176 & Valeninus Gadowski & 1884 & Vicarius \\
\hline 177 & Ladislaus Dutkiewicz & 1885 & Vicarius \\
\hline 178 & Hilarius Kocańda & 1885 & Vicarius \\
\hline 179 & Franciscus Gawłowicz & 1886 & Vicarius \\
\hline 180 & Michael Boryczka & 1887 & Vicarius \\
\hline 181 & Michael Ekert & 1887 & Vicarius \\
\hline 182 & Stanislaus Gajewski & 1888 & Vicarius \\
\hline 183 & Josephus Sikora & 1888 & Vicarius \\
\hline 184 & Joaanes Kuderna & 1889 & Vicarius \\
\hline 185 & Andreas Łuczkosiński & 1889 & Vicarius \\
\hline 186 & Karolus Fąferko & 1890 & Praepositus, Decanus \\
\hline 187 & Josephus Jarosz & 1890 & Vicarius \\
\hline 188 & Adalbertus Ścisło & 1890 & Vicarius \\
\hline 189 & Franciscus Gutfiński & 1890 & Vicarius \\
\hline 190 & Franciscus Czernecki & 1890 & Vicarius \\
\hline 191 & Marcellus Piotrowski & 1891 & Vicarius \\
\hline 192 & Josephus Głuc & 1892 & Vicarius \\
\hline 193 & Andreas Pawicki & 1894 & Vicarius \\
\hline 194 & Blasius Kotfis & 1896 & Vicarius, catecheta $^{\mathrm{B}}$ \\
\hline 195 & Andreas Macko & 1895 & Vicarius \\
\hline 196 & Paulus Sulma & 1897 & Vicarius \\
\hline 197 & Ignatius Kołodziej & 1900 & Vicarius \\
\hline 198 & Antonius Janik & 1903 & Vicarius \\
\hline 199 & Stefanus Muller & 1903 & Vicarius, catecheta ${ }^{\mathrm{C}}$ \\
\hline 200 & Franciscus Kmieciński & 1905 & Vicarius, catecheta $^{\mathrm{D}}$ \\
\hline 201 & Valentinus Mucha & 1905 & Vicarius \\
\hline 202 & Stanislaus Nowak & 1906 & Vicarius \\
\hline 203 & Joannes Twardowski & 1907 & Vicarius \\
\hline 204 & Michael Skura & 1908 & Vicarius \\
\hline 205 & Michael Orczyk & 1909 & Vicarius \\
\hline 206 & Joannes Bączyński & 1910 & Vicarius \\
\hline 207 & Joannes Głąb & 1910 & Vicarius \\
\hline 208 & Josephus Wdowiak & 1911 & Vicarius \\
\hline 209 & Paulus Wieczorek & 1913 & Vicarius \\
\hline 210 & Ladislaus Budzik & 1915 & Vicarius \\
\hline 211 & Joannes Bibro & 1917 & Vicarius, 1923 administrator parochiae \\
\hline
\end{tabular}




\begin{tabular}{|c|c|c|c|}
\hline $\begin{array}{l}\text { Numerus } \\
\text { positionis }\end{array}$ & $\begin{array}{l}\text { Nomen et Cognomen } \\
\text { Presbyterorum }\end{array}$ & $\begin{array}{c}\text { Dies et numerus } \\
\text { decreti aplication } \\
\text { Instituonis }\end{array}$ & $\begin{array}{l}\text { Tempus et modus eorum. Adventus } \\
\text { et existentiae cum meritis }\end{array}$ \\
\hline 212 & Florianus Moryl & 1923 & Praepositus, Decanus \\
\hline 213 & Henricus Weryński & 1920 & Catecheta \\
\hline 214 & Stanislaus Wrona & 1924 & Vicarius \\
\hline 215 & Petrus Warecki & 1926 & Catecheta \\
\hline 216 & Josephus Grądziel & 1927 & Vicarius \\
\hline 217 & Adolphus Pacocha & 1929 & Vicarius \\
\hline 218 & Bronislaus Kalisz & 1932 & Vicarius \\
\hline 219 & Joannes Dryja & 1934 & Vicarius \\
\hline 220 & Henricus Arczewski & 1939 & Vicarius \\
\hline 221 & Stefanus Jasica & 1941 & Vicarius \\
\hline 222 & Stanislaus Wilk & 1942 & Vicarius \\
\hline 223 & Casimirus Terlecki & bd & Parochus dioec[esis] Leopol[is] \\
\hline 224 & Stanislaus Pękala & 1945 & Vicarius \\
\hline 225 & Adolphus Pacocha & bd & Residens \\
\hline 226 & Teodorus Badawika & bd & Vicarius \\
\hline 227 & Stanislaus Kolebok & 1946 & Catecheta \\
\hline 228 & Joseph Midura & 1946 & Parochus loci \\
\hline 229 & Michael Wojtasik & 1948 & Vicarius \\
\hline 230 & Miecislaus Stal & 1953 & Vicarius \\
\hline 231 & Kasimirus Kos & 1955 & Vicarius \\
\hline 232 & Andreas Kuźma & 1955 & Vicarius \\
\hline 233 & Joannes Wolan & 1957 & Vicarius \\
\hline 234 & Miecislaus Pytka & 1959 & Vicarius \\
\hline 235 & Bronislaus Skrzek & 1959 & Vicarius \\
\hline
\end{tabular}

A Zachowano orginalny zapis źródła.

B Zob. Schematismus Dioeceseos Tarnoviensis 1898, s. 91; M. Łabuz, Duchowieństwo diecezji tarnowskiej w latach 1886-1918, Tarnów 2007, s. 156.

C Zob. Schematismus Dioeceseos Tarnoviensis 1905, s. 114.

D Zob. Schematismus Dioeceseos Tarnoviensis 1906, s. 124.

Rok 1959 jest ostatnim, do którego doprowadzono Elenchus pilzneński. W tej części zamieszczono 130 nazwisk, z czego ks. Michał Porębski występuje dwukrotnie: pod numerem 130 jako wikariusz i 141 jako proboszcz. Warto zauważyć, że w farze pilźnieńskiej pracowało dziesięciu wikariuszy zakonnych, z reguły pochodzących z klasztorów z terenu diecezji tarnowskiej. Byli to:

- augustianie pilzneńscy (4; poz. 111, 112, 115 i 118): od 1793 r. Mikołaj Brzóska, od 1795 r. Sebald Kopaczyński i Posydiusz Nowakowski oraz od 1797 r. Rafał Bańkowski;

- jeden franciszkanin reformata, być może z pobliskiego Zakliczyna nad Dunajcem (poz. 136): od 1820 r. Paschalis Irzykiewicz,

- jeden franciszkanin obserwant (bernardyn; poz. 143) być może związany z tarnowskim klasztorem bernardynów: od 1827 r. Kanty Rudowski;

- czterech jezuitów: (poz. 138, 139, 140 i 142): od 1827 r. Michał Rypiński, Wincenty Raciborski, Mateusz Kłosowski oraz Augustinus Markiewicz.

W omawianym przedziale czasu parafią pilzneńską zarządzało 7 proboszczów - byli to: 
1. ks. Wojciech Zaborski

2. ks. Michał Porębski

3. ks. Ferdynand Celarski

4. ks. Ignacy Wieniawa Długoszewski

5. ks. Karol Fąferko

6. ks. Florian Moryl

7. ks. Józef Midura
$1785-1825$

$1826-1838$

$1838-1872$

$1872-1890$

1890-1923

1923-1946

1946-1961

Ks. Wojciech Zaborski (ur. 1746 - zm. 20 IX 1825) pochodził ze Starej Jastrząbki. Wyświęcony w 1770 r. Proboszcz w Pilźnie od 26 IX 1785 do 20 IX 1825 r. Był dziekanem dekanatu pilzneńskiego. W 1787 r. na wale miejskim wybudował plebanię, w 1801 r. wikarówkę; wybudował też dom ubogich; w 1800 r. włączył prebendy do uposażenia probostwa. Od 12 XI 1807 r. był oficjałem pilzneńskim, od 24 XII 1800 r. honorowym kanonikiem kapituły tarnowskiej. Brał czynny udział w życiu społecznym miasta. Spoczywa na cmentarzu w Pilźnie ${ }^{11}$.

Ks. Michał Porębski (ur. 1788 - zm. 18 V 1838) święcenia kapłańskie przyjął we Lwowie w 1811 r. Do Pilzna przybył najpierw jako wikariusz; posługiwał w latach 1812-1822. Od 1822 r. został wikariuszem katedralnym i jednocześnie sekretarzem biskupa G.T. Zieglera, od 1823 r. profesorem katechetyki i metodyki w Seminarium Duchownym w Bochni, od 1826 r. pierwszym ojcem duchownym w seminarium. Proboszczem w Pilźnie został 2 VII 1826 r. i był nim aż do śmierci (1838). Sprawował funkcję dziekana dekanatu pilzneńskiego, inspektora szkół ludowych, egzaminatora prosynodalnego z teologii pastoralnej. Spoczywa na cmentarzu w Pilźnie ${ }^{12}$.

Ks. Ferdynand Celarski (ur. 21 I 1808 - zm. 15 II 1872) pochodził z Jodłowej. Był kapłanem diecezji przemyskiej, gdzie otrzymał święcenia w 1831 r. z rąk bpa J. Potockiego. W 1858 r. przeniósł się do diecezji tarnowskiej i został proboszczem w Pilźnie. Urząd ten piastował od 18 X 1838 r. do 13 II 1872 r. Sporządził Elenchus - wypis księży posługujących w pilźnieńskiej parafii. Podczas rzezi galicyjskiej urządził na rynku procesję z Najświętszym Sakrametem w celu uproszenia Bożej Opatrzności dla mieszkańców miasta, co nie spotkało się z akceptacją zgromadzonego tłumu. Był dziekanem dekanatu pilzneńskiego i inspektorem szkół ludowych. W 1857 r. został honorowym kanonikiem kapituły tarnowskiej. W 1862 r. podjął się trudu odnowienia wnętrza fary pilzneńskiej (malowanie). Spoczywa na cmentarzu w Pilźnie. Odznaczony był EC i RM ${ }^{13}$.

Ks. Ignacy Wieniawa Długoszewski (ur. 4 VII 1819 - zm. 19 V 1890) pochodził z Falkowej k. Nowego Sącza. Święcenia kapłańskie otrzymał z rąk bpa J. Wojtarowicza 28 VIII 1842 r. Za angażowanie się w wydarzenia rewolucyjne 1846 r. skazany we Lwowie w 1847 r. na karę śmierci przez powieszenie, co ostatecznie zmienione zostało na 8 lat więzienia w Spielbergu. Ułaskawiono go dzięki wstawiennictwu bpa Wojtarowicza. Był wikariuszem

\footnotetext{
11 B. Kumor, Diecezja tarnowska, dz. cyt., s. 89, 90, 95; A. Nowak, Zaborski Wojciech (1746-1825), w: Stownik Biograficzny Kapłanów Diecezji Tarnowskiej (dalej: SBKDT), t. 4, Tarnów 2004, s. 229.

12 [R. Banach], Ojcowie duchowni Seminarium Duchownego w Bochni i Tarnowie, w: Schematyzm diecezji tarnowskiej na rok 1992. Część historyczna, Tarnów 1992, s. 73; A. Nowak, Porębski Michał (1788-1838), w: SBKDT, t. 3, Tarnów 2001, s. 327.

13 K. Szczeklik, Pilzno i pilźnianie, Kraków 1911, s. 81; B. Kumor, Diecezja tarnowska, dz. cyt., s. 551; A. Nowak, Celarski Ferdynand Anastazy (1808-1872), w: SBKDT, t. 2, Tarnów 2000, s. 108.
} 
w Starym Sączu i Wojniczu, a następnie proboszczem w Grybowie. Probostwo w Pilźnie objął 4 IX 1872 r. Urząd ten sprawował aż do śmierci (1890). W dekanacie pilzneńskim od 1883 r. był dziekanem, od 1885 r. inspektorem szkół ludowych. Dla pilzneńskiej fary w 1887 r. zakupił ołtarz główny z białego piaskowca. Odznaczony EC i RM, od 1888 r. był kanonikiem honorowym kapituły tarnowskiej. Spoczywa na cmentarzu w Pilźnie ${ }^{14}$.

Ks. Karol Fąferko (ur. 24 X 1849 - zm. 18 VIII 1923) pochodził z Wadowic. Święcenia przyjął w Tarnowie 13 VII 1872 r. z rąk bpa J. Pukalskiego. Proboszczem w Pilźnie był od 14 X 1890 r. do 18 VIII 1923 r. Troszczył się o pilzneńską farę: w 1893 i 1902 r. zakupił w Tyrolu ołtarze boczne (ołtarz Serca Pana Jezusa jest jego fundacji), w 1889 r. nową marmurową chrzcielnicę, w 1899 r. Drogę Krzyżową (także w Tyrolu), a w 1909 r. świątynię ozdobiono secesyjną polichromią. W 1908 r. wybudował dom dla organisty i kościelnego. Od 14 XI 1890 r. był dziekanem dekanatu pilzneńskiego. Aktywnie udzielał się społecznie. Słynął z ziołolecznictwa, udzielał porad lekarskich i leczył choroby serca. Odznaczony był EC i RM, a z okazji złotego jubileuszu kapłaństwa został mianowany podkomorzym Jego Świątobliwości. Spoczywa na cmentarzu w Pilźnie ${ }^{15}$.

Ks. Florian Moryl (ur. 5 V 1875 - zm. 30 V 1946) pochodził z Kars k. Gręboszowa. Do seminarium wstąpił w Tarnowie i 29 VI 1899 r. z rąk bpa I. Łobosa przyjął święcenia kapłańskie. Proboszczem w Pilźnie został 10 XII 1923 r., od 4 XII 1924 r. był wicedziekanem, a od 13 I 1927 r. dziekanem pilzneńskim. Tu przeżył II wojnę światową. Odznaczony był EC i RM. Spoczywa na cmentarzu w Pilźnie ${ }^{16}$.

Ks. Józef Midura (ur. 18 I 1905 - zm. 25 VIII 1974) pochodził z parafii Wadowice Górne. Seminarium duchowne ukończył w Tarnowie, przyjmując 29 VI 1930 r. święcenia kapłańskie z rąk bpa L. Wałęgi. Do Pilzna przybył w 1946 r. i proboszczował do 1961. Od 26 XI 1956 r. do 2 III 1961 r. był dziekanem pilzneńskim. Był dobrym gospodarzem dbającym o kościół (przebudował dach). Na skutek nieporozumień z parafianami zrezygnował z funkcji proboszcza w Pilźnie i przeniósł się do Zaborowa. Odznaczony był EC i RM. Spoczywa na cmentarzu w Zaborowie ${ }^{17}$.

Zachowany Elenchus ks. Ferdynanda Celarskiego pozwala odtworzyć listę duchownych zaangażowanych w posługę i funkcjonowanie pilźnieńskiej parafii w omawianym przedziale od roku 1786 aż do 1959 r., czyli blisko 180 lat. Jest to doskonałe źródło prozopograficzne, uzupełniające wiedzę na temat fary pw. św. Jana Chrzciciela w Pilźnie, odzwierciedlające stan osobowy kapłanów diecezjalnych (diec. tarnowska) oraz kapłanów zakonnych, którzy na przestrzeni lat 1786-1959, pełniąc różne funkcje, pracowali też jako wikariusze pilzneńscy. Spis sporządzony przez ks. Ferdynanda Celarskiego wpisuje się w bieg dziejów parafii pilzneńskiej poprzez ocalenie od zapomnienia duchownych, którzy tworzyli historię tej parafii. Stanowi bazę źródłową do dalszych pogłębionych badań prozopograficznych.

\footnotetext{
14 K. Szczeklik, Pilzno i Pilźnianie, Pilzno 1996, s. 52-53; A. Nowak, Dlugoszewski Ignacy herbu Wieniawa (1819-1890),w: SBKDT, t. 2, Tarnów 2000, s. 153-154.

15 J. Jabłoński, T. Popiela, S. Tomasiewicz, Pilzno. Kościoły i kaplice parafii pilźnieńskiej na przestrzeni dziejów, Krosno 2004, s. 68; A. Nowak, Faferko Karol (1849-1923), w: SBKDT, t. 2, Tarnów 2000, s. 191.

16 F. Celarski, Elenchus. Omnium Parochorum, Administratorum, Capellanorum localium, Cooperatorum Parochiae Pilzno, rps, s. 17; A. Nowak, Celarski Ferdynand Anastazy (1808-1872), w: SBKDT, t. 3, Tarnów 2001, s. 224.

17 J. Mleczko, Śp. Ks. Józef Midura (1905-1974), „Currenda”, 126/1976, s. 94-95; A. Nowak, Midura Józef(19051974), w: SBKDT, t. 3, Tarnów 2001, s. 205-206.
} 